\title{
EARTHMOVING PRODUCTIVITY ESTIMATION USING GENETIC ALGORITHM
}

\author{
K. M. Shawki; \\ Assistant Professor, construction and building engineering Dept. Collage \\ of Engineering and Technology Arab Academy for Science, Technology \\ and Martine Transport-Alexandria-Egypt
}

\section{E. Abd EL-Razek and}

Head of construction and building engineering Dept. Collage of Engineering and Technology Arab Academy for Science, Technology and Martine Transport Cairo Egypt

\section{N. Abdulla \\ Post graduate student construction and building engineering Dept. Collage of Engineering and Technology Arab Academy for Science, Technology and Martine Transport Alexandria-Egypt. \\ (eng_nour1980@yahoo.com)}

(Received April 30, 2009 Accepted May 11, 2009)

This paper presents a framework for optimizing earth moving operations using computer simulation and genetic algorithms (GA) as an optimizer. The optimization aims at maximizing production of an earth moving fleet consists of an excavator and trucks as hauling units. The objective function considers the variables that influence the production of earth moving operations such as rolling resistance, grade resistance, vehicle weight, payload, horse power..etc. The constraints of the objective function are considered such as speed limits, payload capacity, etc. A sizing problem is considered to tune the GA parameters such as selection, crossover, population size, mutation, etc. Numerical examples are presented using developed software called "FLEET PRODUCTION" to illustrate the practical features of the proposed software and to demonstrate its capacities in selecting optimum fleet configurations. "FLEET PRODUCTION" is designed to assist engineers and contractors to select the best fleet combination of hoe and haulers that can complete an earth moving operation with maximum production.

KEYWORDS: Genetic Algorithms, Construction equipment, Productivity

\section{INTRODUCTION}

Earthmoving operations are a major part of many civil engineering projects and have long been the subject of investigations into estimating their output prior to actual commencing site work. Numerous techniques have been established to provide such estimates with varying degrees of success. Generally speaking, the earthmoving projects are performed using hoe and multiple trucks; the selection of fleet for the earthmoving projects is traditionally based on experience. Practically speaking, the tendency of the 
decision makers in the earthmoving projects is to use the on hoe - trucks system. The hoe - truck size is basically selected based on the production required per hour. Schexnayder and Hancher [1] take into consideration that 1950s and early 1960s introduction of several new technologies and materials helped to increase the rate of equipment productivity at a rapid pace.

Griffis [2] and Cabrera [3] developed a mathematical model based on the queuing theory, these models depend on the sustained productivity rather than the instantaneous production calculated in other deterministic models such as Gates and Scarp [4] and Aitcheson [5]. Yau and Yang [6] developed a model to estimate construction duration and costs of building construction projects. Besides, Yau and Yang [6] developed a model to estimate productivity rates of variability in the overall productivity of the operation. Gransberg [7] developed a model that relies on the derivation of a cost index number to determine the optimum size and number of haul units for the given loading facility. Marzouk and Moselhi [8] developed models based on genetic algorithms. Finally Marzouk, [9] developed model for equipment selection based on utility theory.

\section{EARTHMOVING PRODUCTIVITY}

The production of a fleet consist of an excavator (hoe) and number of haulers (trucks) can be determined from the equation $[10,11]$ :

$$
\text { Production }=\text { Truck } \cdot \text { load }^{*} \text { Nubmer. of } \cdot \text { trucks } * \frac{60 \mathrm{~min}}{\text { Truck } \cdot \text { cycle } \cdot \operatorname{time}(\min )}
$$

The truck cycle time can be determined from the equation:

Truck $\cdot$ cycle $\cdot$ time $=$ load $\cdot$ time + haul $\cdot$ time + dump $\cdot$ time + return $\cdot$ time $\ldots$.

Load $\cdot$ time $=N_{b} \times L_{c t}$

Where; $\mathrm{N}_{\mathrm{b}}=$ number of buckets; $\mathrm{L}_{\mathrm{ct}}=$ hoe cycle time

The truck velocity can be determined from the equation:

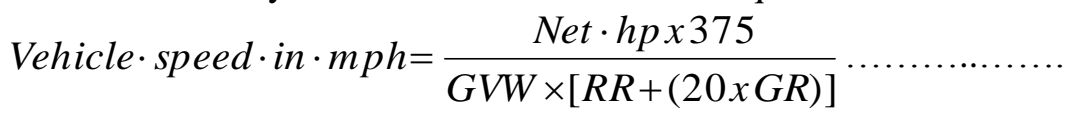

Where GVW = Gross vehicle weight; $\mathrm{RR}=$ rolling resistance; $\mathrm{GR}=$ Grade resistance for hauling $\mathrm{GR}=\mathrm{PG}_{\mathrm{h}}$, for return $\mathrm{GR}=\mathrm{PG}_{\mathrm{r}}$

The hauling time is as follows:

$$
\text { Haul } \cdot \text { time } \cdot\left(T_{h}\right)=7.3 \times 10^{-6} \frac{N_{W}+\left(N_{b} V_{b} U_{W}\right)\left(R R+20^{*} P G_{h}\right)}{h p} \ldots \ldots \ldots .
$$

The return time is as follows:

$\operatorname{Return} \cdot \operatorname{time}\left(T_{R}\right) \cdot=7.3 \times 10^{-6} \frac{L_{h} N_{W}\left(R R+20 \times P G_{r}\right)}{h p}$

Applying those times in equation (1) leads to the following final objective function:

$$
\text { Production }=\frac{3600 \mathrm{~N}_{\mathrm{t}} \mathrm{N}_{\mathrm{b}} \mathrm{V}_{\mathrm{b}}}{\left(7.3 \times 10^{-6} \frac{L_{h}\left(N_{W}+N_{b} V_{b} U_{W}\right)\left(R R+20 x P G_{h}\right)}{H p}+7.3 \times 10^{-6} \frac{L_{h} N_{W}\left(R R+20 x P G_{r}\right)}{H p}+N_{b} L_{c t}+D_{t}\right)}
$$


Where $\mathrm{N}_{\mathrm{t}}=$ number of trucks; $\mathrm{N}_{\mathrm{b}}=$ number of buckets; $\mathrm{V}_{\mathrm{b}}=\operatorname{volume}$ per bucket $\left(\mathrm{m}^{3}\right) ; \mathrm{L}_{\mathrm{h}}$ = haul length $(\mathrm{m}) ; \mathrm{N}_{\mathrm{w}}=$ net empty vehicle weight $(\mathrm{kg}) ; \mathrm{U}_{\mathrm{w}}=$ unit weight $\left(\mathrm{kg} / \mathrm{m}^{3}\right)$; $\mathrm{PG}_{\mathrm{h}}=$ grade resistance in hauling direction $(\%) ; \mathrm{PG}_{\mathrm{r}}=$ grade resistance in return direction $(\%) ; \mathrm{D}_{\mathrm{t}}=$ dumping time (sec); $\mathrm{Hp}=$ truck house power; $\mathrm{L}_{\mathrm{ct}}=$ hoe cycle time; $\mathrm{RR}=$ rolling resistance .

The aim of the analysis is to maximize the objective function satisfying the following constraints, The number of buckets is three to six for practical purposes, the number of trucks is greater than one and the product of and the safe payload for truck must be satisfied.

\section{BASIC IDEA OF STANDARD GENETIC ALGORITHMS}

Genetic Algorithms (GAs) were first presented by J. H. Holland "Natural and Artificial Systems" in the year 1975 [12] and developed further by his students. Also genetic algorithms are a compromise between "weak" and "strong" search method Goldberg [13].With time, many changes and improvements have been suggested. Here, we discuss the present form of implementation of Genetic Algorithms. Genetic algorithms are a class of algorithms inspired by evolution. These algorithms encode solutions to a specific problem on a simple chromosome like data structure and apply recombination operators to these structures so as to preserve critical information.

An implementation of a genetic algorithm begins with a population as shown in Fig (1) of (typically random) chromosomes. Then these structures are evaluated and allocated reproductive opportunities in such a way that those chromosomes which represent a better solution to the problem are given more chances to reproduce than those chromosomes which are poorer solutions. The "goodness" of a solution is typically defined with respect to the current population.

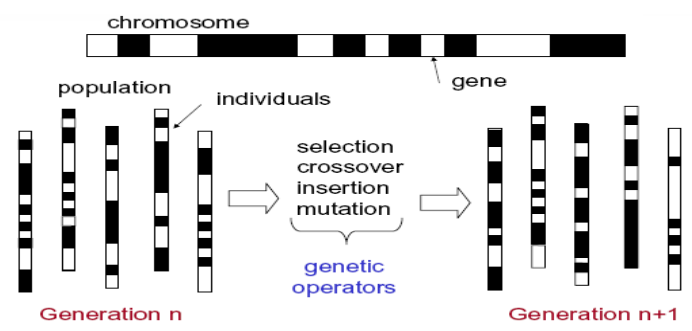

Figure (1) GAs Elements

\section{THE BASIC STEPS INVOLVED IN A GA ARE THE FOLLOWING}

Build an initial population of samples (solutions) created randomly or using some initialization method. Calculate the fitness (measure of being provided reproductive opportunities) of all the samples and select individuals for the reproduction process. The selection of the individual is though based on fitness, but it is a probabilistic mechanism. Roulette wheel selection, Rank Tournament Selection, Stochastic Universal Selection are some of the selections used.

Apply the genetic operators of crossover, mutations,.etc. to the selected individuals to create new individuals and thus a new generation. Crossover exchanges 
some of the bits of the two chromosomes and mutation inverts any bit(s) of the chromosome depending on a probability. A crossover is a distinguishing feature of genetic algorithms.

Many evolutionary algorithms were earlier used, but they basically worked on mutations and no crossovers took place. In GAs crossovers 'explore' around the already found good solutions and mutations help 'exploiting' the search space for new solutions.

\section{TUNNING OF GA PARAMETERS}

MATLAB software was used to solve the problem under consideration. The genetic algorithm parameters must be tuned using standard problem. The standard problem consists of a hoe and trucks with known configurations. The haul route is known. The GA parameters such as generation number, population size, crossover type, type of selection and probability of mutation will be examined to find the recommended values. The domain of each parameter is set as shown in Table (1).

Table (1) GA Parameters Domains

\begin{tabular}{|l|c|}
\hline \multicolumn{1}{|c|}{ Item } & Domain \\
\hline Number of generations & $0-50$ \\
\hline Population size & From 50 to 200 \\
\hline Probability of crossover & Single ,two point \\
\hline Probability of Selection & Roulette, stochastic uniform,.... \\
\hline Probability of mutation & From 1\% to $10 \%$ \\
\hline
\end{tabular}

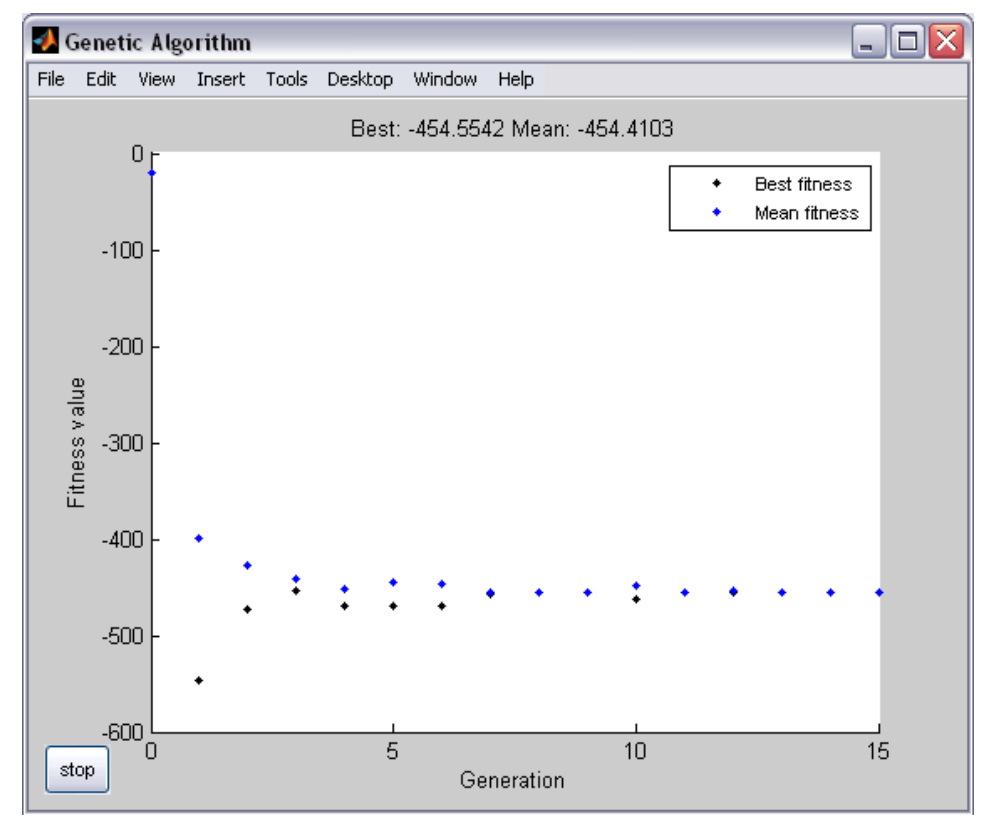

Figure (2) Relationship between 15 generation and fitness value 


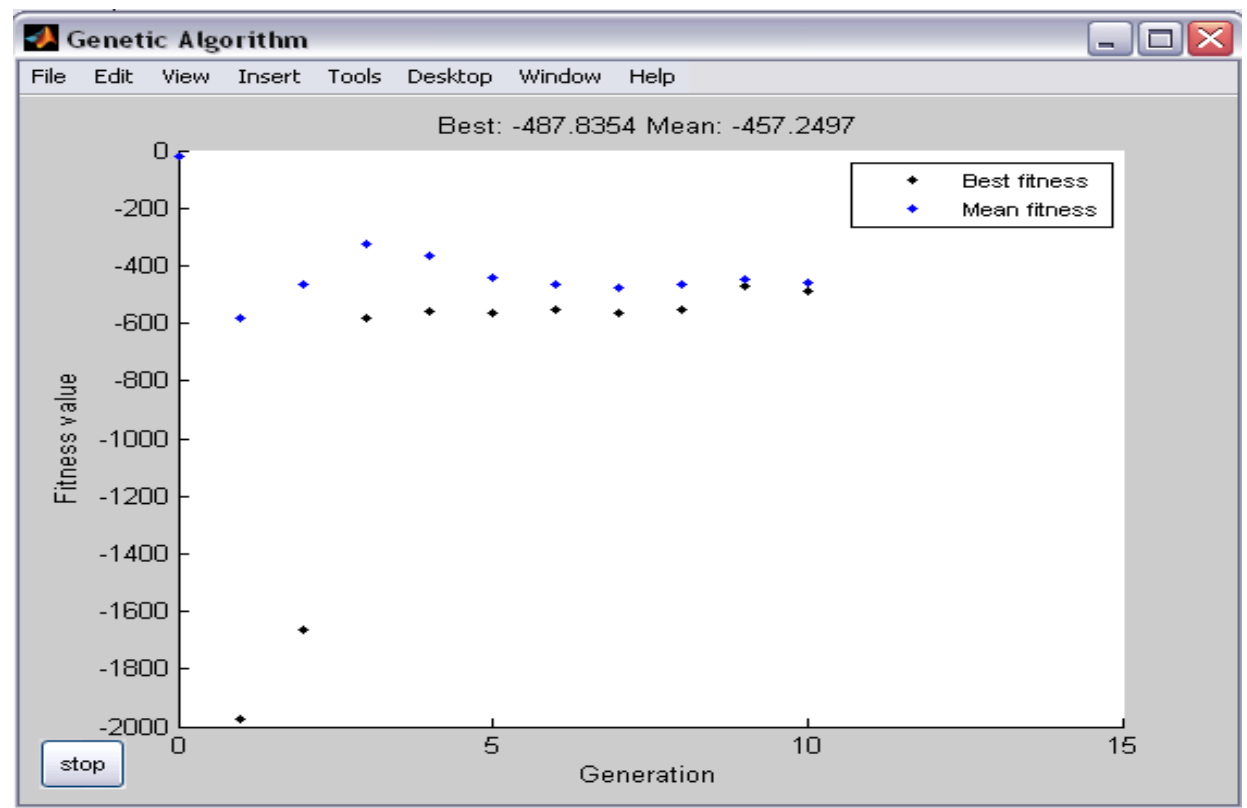

Figure (3) The effect of selection on the production

Table (2) GA Parameters used in Fig (3)

\begin{tabular}{|c|c|}
\hline Population type & Double vector \\
\hline Population size & 80 \\
\hline Selection function & Roulette \\
\hline Mutation function & adaptive feasible \\
\hline Crossover function & scattered \\
\hline
\end{tabular}

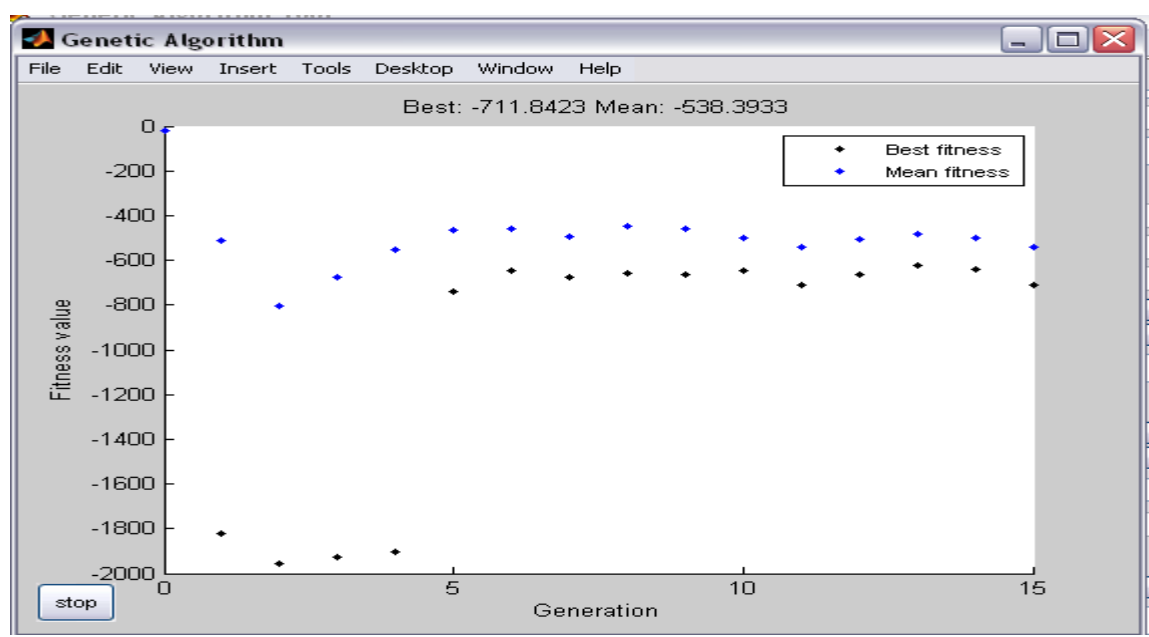

Figure (4) The effect of selection on the production 
Table (3) GA Parameters used in Fig (4)

\begin{tabular}{|c|c|}
\hline Population type & Double vector \\
\hline Population size & 100 \\
\hline Selection function & stochastic uniform \\
\hline Mutation function & $(0.08)$ \\
\hline Crossover function & Intermediate $(0.7)$ \\
\hline
\end{tabular}

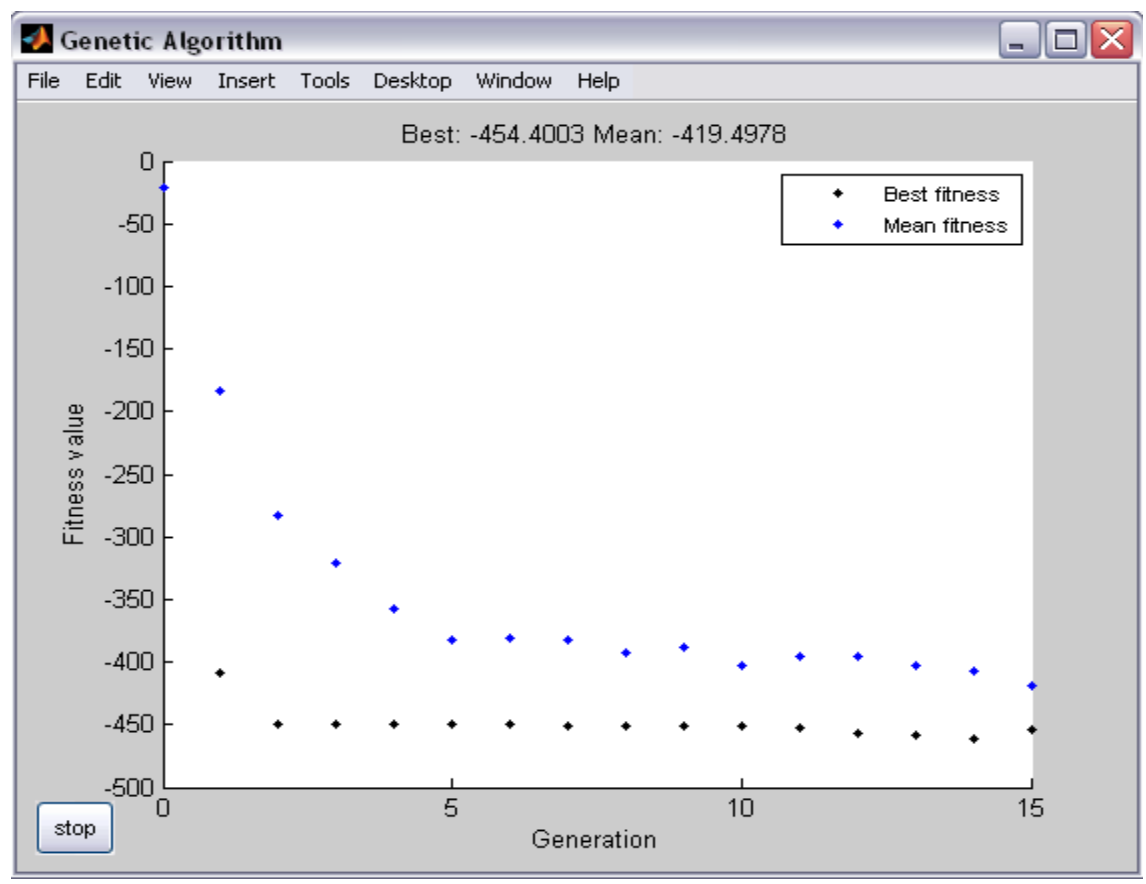

Figure (5) The effect of crossover to gather on the production at the stander generation to evaluate fitness value.

Table (4) GA Parameters used in Fig (5)

\begin{tabular}{|c|c|}
\hline Population type & Double vector \\
\hline Population size & 100 \\
\hline Selection function & Roulette \\
\hline Mutation function & $(0.06)$ \\
\hline Crossover function & Two point \\
\hline
\end{tabular}

Figure (2) illustrates the effect of generations on the performance of the procedure. Figure (3) shows the effect of selection on the production at the stander generation to evaluate fitness value 
Figure (4) shows the effect of selection on the production at the stander generation to evaluate fitness value

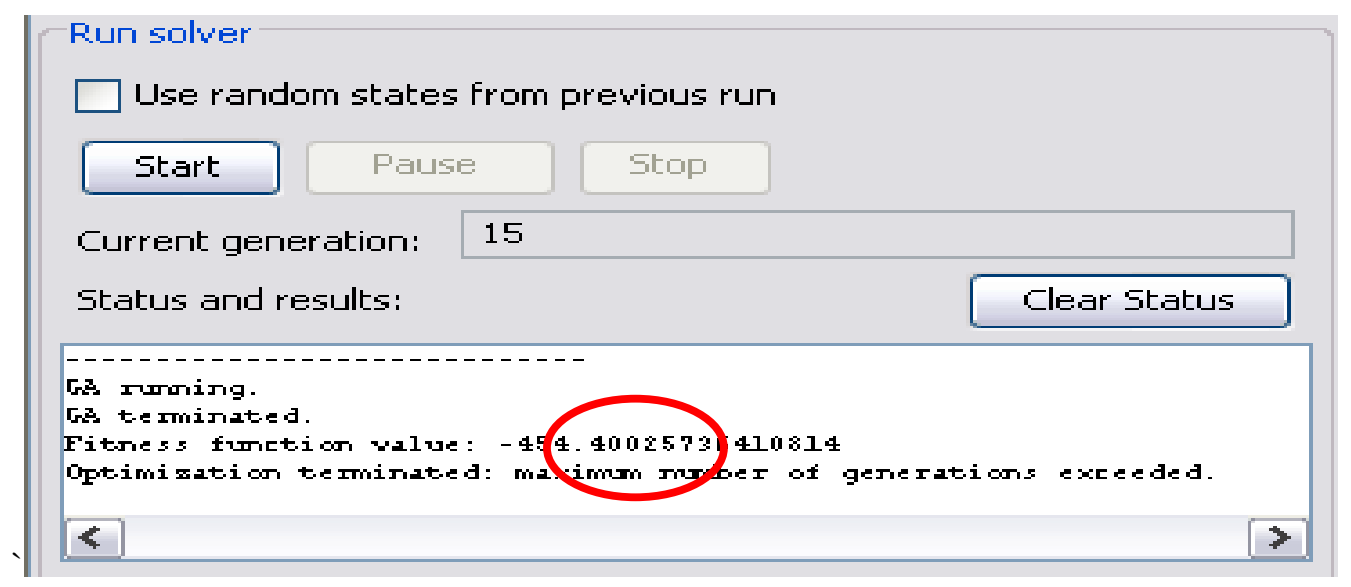

Figure (6) Final results

From the above study it can be conclude that the tuned GA parameters are listed in Table (5).

Table (5) GA Parameters

\begin{tabular}{|c|c|}
\hline Number of generations & 15 \\
\hline Population size & 100 \\
\hline Probability of crossover & two point \\
\hline Probability of Selection & Roulette \\
\hline Probability of mutation & 0.06 \\
\hline
\end{tabular}

\section{PROPOSED MODEL (FLEET PRODUCTION)}

The FLEET PRODUCTION is a prototype computer model designed as a standalone module to assist engineers and contractors to select the best fleet combination of hoe and haulers that can complete an earth moving operation with maximum production .FLEET PRODUCTION is dynamically linked to GA in MATLB.

The user of FLEET PRODUCTION, as shown in Fig (7), is required to specify the scenario number. The user then specifies the road data such as grade resistance in the hauling and return directions, soil unit weight, and haul distance. The user chooses the hoe type from the listed type saved in FLEET PRODUCTION if the required hoe does not existed, the user can edit his own hoe specifications using the edit button, the hoe edit dialog box shown in Fig (8). Also the user can choose the truck type from the listed type saved in FLEET PRODUCTION if the required truck does not existed, the user can edit his own truck specifications using the edit button, the truck edit dialog box shown in Fig (9). 




Fig (7) Fleet Production Interface

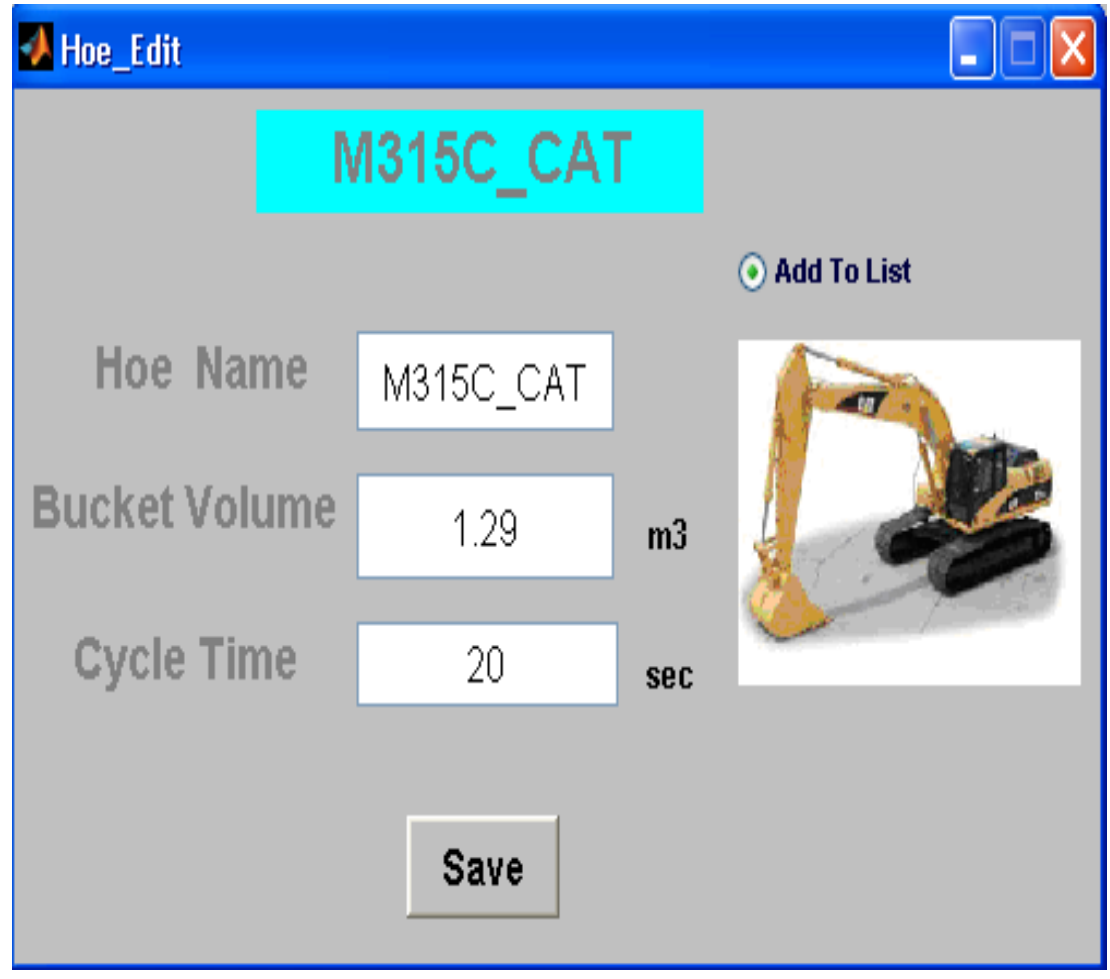

Fig (8) Hoe Edit Dialog Box 


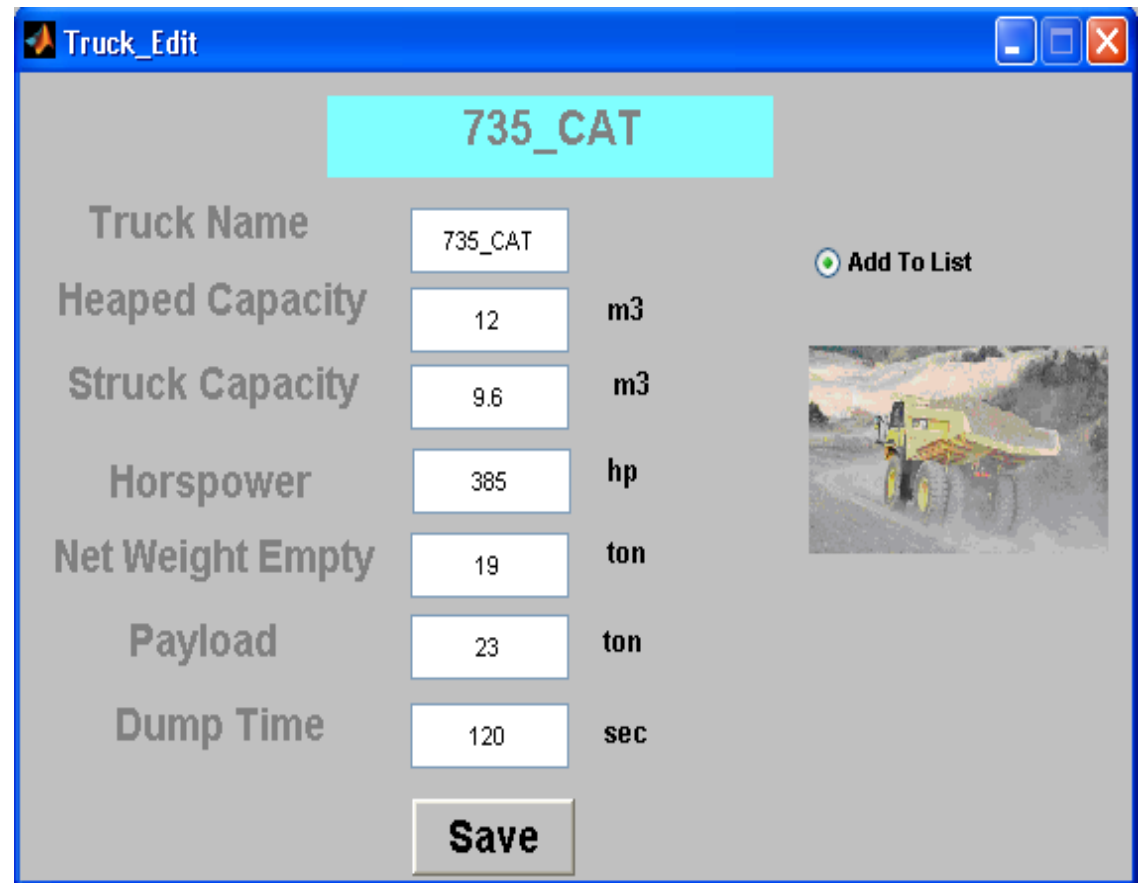

Fig (9) Truck Edit Dialog Box

\section{NUMERICAL EXAMPLES}

To illustrate the ability of the proposed system in selecting maximum production of fleet consists of hoe and trucks as haulers in earthmoving operations, seven examples are analyzed. Each example, as shown in Table (6), contains the haul distance from the site to the dump area, the grade resistance in both hauling and return and the payload type. Tables (7) and (8) represent the available hoes and trucks specifications.

Table (6) Road Configurations

\begin{tabular}{|c|c|c|c|c|}
\hline No Run & $\begin{array}{c}\text { Haul } \\
\text { Distance } \\
(\mathrm{m})\end{array}$ & $\begin{array}{c}\text { Percent of } \\
\text { Grade } \\
\text { Haul \% }\end{array}$ & $\begin{array}{c}\text { Percent of } \\
\text { Grade } \\
\text { Return \% }\end{array}$ & Capacity Type \\
\hline 1 & 1000 & 5 & 7 & Heaped \\
\hline 2 & 2000 & 2 & 5 & Heaped \\
\hline 3 & 3000 & 4 & 6 & Heaped \\
\hline 4 & 5000 & 3 & 4 & Heaped \\
\hline 5 & 7000 & 6 & 8 & Heaped \\
\hline 6 & 9000 & 7 & 9 & Heaped \\
\hline 7 & 11000 & 1 & 3 & Heaped \\
\hline
\end{tabular}


Table (7) Hoes Specifications

\begin{tabular}{|cl|c|}
\hline \multicolumn{2}{|c|}{ Model } & Bucket volume (m3) \\
\hline M313C & CAT & 0.49 \\
\hline M316C & CAT & 1.29 \\
\hline M316C & CAT & 2.0 \\
\hline M318C & CAT & 2.48 \\
\hline M322C & CAT & 3.0 \\
\hline
\end{tabular}

Table (8) Trucks Specifications

\begin{tabular}{|c|c|c|c|c|c|c|}
\hline Model & $\begin{array}{c}\text { Horsepo } \\
\text { wer }\end{array}$ & $\begin{array}{c}\text { Struc } \\
\mathrm{k} \\
(\mathrm{m} 3)\end{array}$ & $\begin{array}{c}\text { Heaped } \\
(2: 1) \\
\mathrm{m} 3\end{array}$ & $\begin{array}{c}\text { Net } \\
\text { weight } \\
\text { empty } \\
\text { (ton) }\end{array}$ & $\begin{array}{c}\text { Payload } \\
\text { (ton) }\end{array}$ & $\begin{array}{c}\text { Gross, } \\
\text { vehicle } \\
\text { weight (ton) }\end{array}$ \\
\hline 725 CAT & 301 & 4.5 & 6 & 12 & 14 & 26 \\
\hline 730 CAT & 317 & 6.0 & 8 & 14 & 16.2 & 30.2 \\
\hline 730 Ejector & 317 & 7.8 & 10 & 17 & 18.7 & 35.7 \\
\hline 735 CAT & 385 & 8 & 12 & 19 & 23 & 42 \\
\hline 740 CAT & 436 & 11.4 & 14 & 21.5 & 25.8 & 47.3 \\
\hline 740 Ejector & 436 & 13.8 & 16 & 23 & 27 & 50 \\
\hline
\end{tabular}

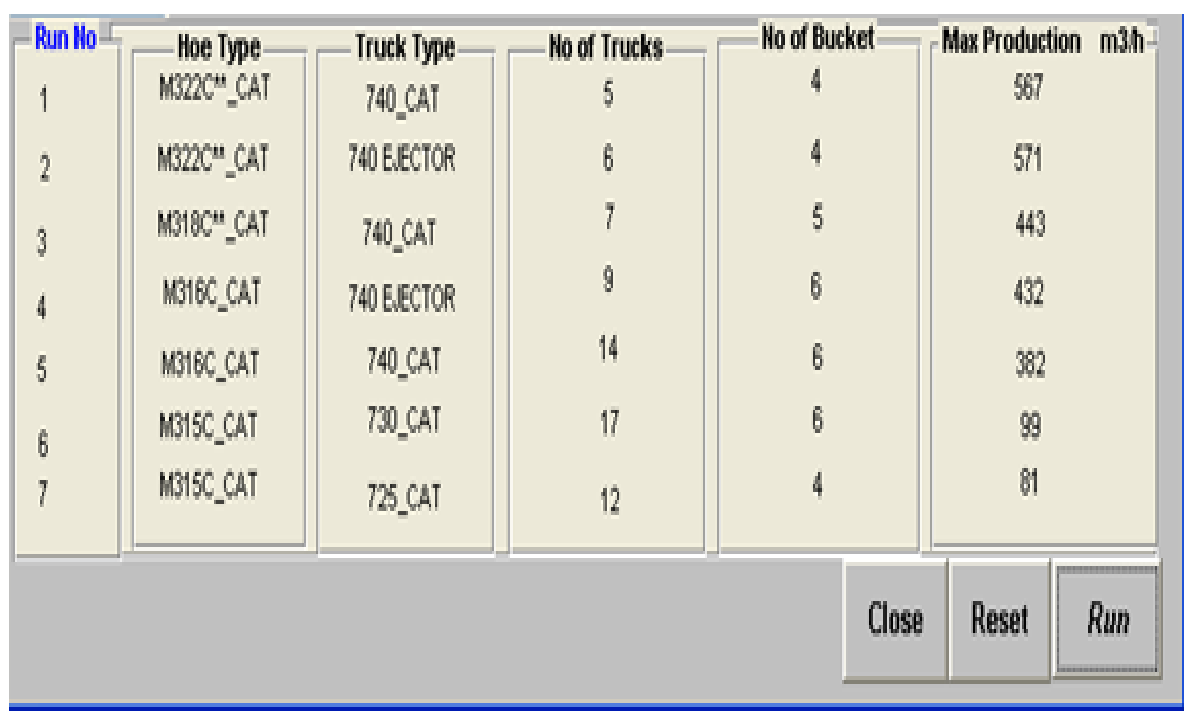

Fig (10) Recommended Fleet Configuration Dialog Box 
Referring to Fig (10) it can be seen that the system select the hoe and truck type to maximize possible output from the earthmoving system as determined by the output of the simulation. For each example in addition to the maximum production the numbers of buckets and trucks to satisfy the production to be maximized are also given.

\section{CONCLUSIONS}

This paper presented a computer model "FLEET PRODUCTION" for equipment fleet selection for earthmoving operation using genetic algorithms and simulation .Fleet production is designed to assist engineers and contractor's foe earthmoving projects in selecting the best equipment fleet system consists of an excavator (hoe) and hauling units (trucks) to maximize production. Fleet production is designed for easy and simple use for engineers and contractors.

The link between genetic algorithm and simulation has been done to solve a wide variety of equipment to get the ideal productivity and efficiency of earthmoving operations to find the best solution.

\section{REFERENCES}

1. Schexnayder, C. J. Jr., And Hancher, D. E.1982. "Inflation and Equipment Replacement Economics.' J. Constr. Eng. Manage., 1082, 289-298.

2. Griffis, F.H.1968, Optimizing Haul Fleet Size Using Queuing Theory, Proc. Asce, Journal of Construction Division, Vol.94, Pp.75-87.

3. Cabrera, J.G, and Maher. M.J.1973, Optimizing Earthmoving Plant: Solution For The Excavator-Trucks System, Highway Research Record No.454, Pp.7-15.

4. Gates, M., And Scarpa, A. 1975, Optimum Size Of Hauling Units, Journal Of Construction Division, Asce, Vol. 101, No .4, 853-860.

5. Aitcheson, D.B.1993, Earthmoving Equipment Production Rates and Costs, Norseman Publishing Co, Venice, Fla, 6-32-6-34.

6. Yau N-J, Yang J-B.1998, Case-Based Reasoning in Construction Management. Comput-Aid Civil Infrastruct Engng, 13(2):143-50

7. Gransberg, D.D.1996, Optimizing Haul Unit Size And Number Based On Loading Facility Characteristics, Journal Of Construction Engineering And Management. Vol.122, No.3, September.

8. Mohamed Marzouk, and Osama Moselhi.2002. Selection Earthmoving Equipment Fleets Using Genetic Algorithms, Construction Management And Economics Journal.

9. Marzouk, M.2006, Utility Theory Model for Equipment Selection, Journal of Construction Engineering and Management. 6: 21-32.

10. Robert L. Peurifoy, P.E. 1996. Construction Planning, Equipment, and Methods. Fifth Edition, the Mc Graw-Hill Companies.

11. Frank Haris.1994, Modern Construction and Ground Engineering Equipment and Methods, Second Edition, Longman Group Uk Limited.

12. Holland J. H, 1975. Adaptation in Natural and Artificial Systems. University Of Michigan Press, Ann Arbor, Mi. 
13. David E .Goldberg D, 1989. "Genetic Algorithms in Search, Optimization\& Machine-Learning". Addison-Wesley Publishing Co., January.

\section{استنتاج انتاجية معدات نقل الاتربة باستخدام الخوارزمات الجينية}

يقدم هذا البحث اطارا لكيفية حساب الانتاجية المثالية لمعدات الحفر في مواقع التثبد باستخدام


خلفي و مجموعة من السيارات ـ و تتكون دالة الهدف من مجموعة المتغيرات التي تؤثر في الانتاجية مثل


المثال في حدود سرعة السيارات من الموقع الي المقالب العموميةو حمولة السيارات وغيرها من القيود الاخري. و قد نم عمل نموذح علي الحاسب الالي باسم FLEET PRODUCTION" سهل الاستخدام

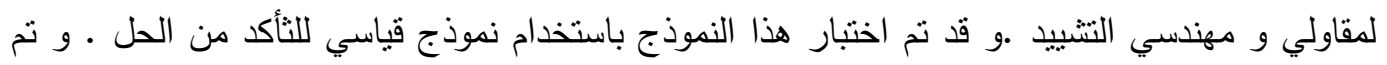
تطبيق هذا النموذج علي مجموعة من الحالات للحصول علي اقصي انتاجية لمنظومة الحفر . 